\title{
Smoking and Peer Preference in College Students: an exploratory study
}

\author{
Prachi Chivate ${ }^{1}$, Maithili Umate ${ }^{2}$, Swateja Nimkar ${ }^{3}$,Rebeka Mercker ${ }^{4}$, Sagar Karia ${ }^{5}$, \\ Avinash De Sousa ${ }^{6}$
}

${ }^{1}$ Resident Doctor, Department of Psychiatry, Grant Government Medical College, Mumbai

${ }^{2}$ Associate Professor, Department of Psychiatry, Grant Government Medical College, Mumbai.

${ }^{3}$ Assistant Professor of Health Services, University of Southern Indiana, Evansville, USA.

${ }^{4}$ Pre-Med/ Public Health Student, University of Southern Indiana, Evansville, USA.

${ }^{5}$ Assistant Professor, Department of Psychiatry, Lokmanya Tilak Municipal Medical College, Mumbai.

${ }^{6}$ Research Associate, Department of Psychiatry, Lokmanya Tilak Municipal Medical College, Mumbai.

Corresponding author: Maithili Umate

Email-maithilikadam@yahoo.com

\begin{abstract}
Background: Smoking in adolescents is related to multiple factors like genetics, family variables and peer preference and influence. The aim of the following study was to study the prevalence of smoking and age of initiation college students while comparing peer preferences in smoker and non-smoker college students.

Methods: 100 college students were divided on the basis of current smoking status into two groups. These two groups were administered the Evers-Pasquale peer preference test and the Global Youth Tobacco Survey (GYTS). Sociodemographic variables were assessed using a semi-structured proforma. The data was then statistically analysed.

Results: The prevalence of current smoking was $54 \%$. Almost $44 \%$ of college students had initiated smoking at or after 16 years of age, whereas only $4 \%$ of the entire sample had initiated smoking before 10 years of age. Close to one fifth $(18.52 \%)$ of current smokers smoked daily and smoked cigarettes first in morning suggesting dependence. Students who currently smoked were most likely to engage in any activity in the company of best friends, followed by cool friends $(p=0.0001)$.

Conclusion: Smoking and peer pressure are linked and there is a need for tobacco intervention programmes to be directed at adolescent specific factors. Further research is needed to understand other factors promoting smoking like personality factors, social influence, genetic factors etc.
\end{abstract}

ABSTRACT

Keywords: Smoking, peer pressure, peer influence, tobacco, adolescents, college.

(Paper received $-4^{\text {th }}$ June 2019 , Peer review completed $-7^{\text {th }}$ August 2019)

(Accepted $-10^{\text {th }}$ September 2019)

\section{INTRODUCTION}

By 2030, tobacco is expected to be the single biggest cause of death worldwide, accounting for about 7 million deaths a year [1]. Cigarette smoking is more detrimental for health than many other forms of tobacco. Smoking is more common in nonmetropolitan areas with lower socioeconomic status and lower level education [2]. Tobacco consumption is increasing in developing countries with a lower age of initiation of smoking in adolescents [3]. A disturbing trend is seen in developing countries like India with adolescents and children initiating smoking. Though tobacco consumption is decreasing in Western countries [4], the prevalence of smoking in adolescents has increased in the last 40 years [5].

Smoking in adolescents is related to long term dependence, severity of smoking and higher morbidity and mortality [6]. Initiation of smoking is complex with contribution of social, environmental, cognitive, and genetic influences [7]. Some researchers suggest that instead of direct peer pressure to smoke, adolescents 
attribute smoking to trying to conform to a group. According to selection theory, adolescents choose friends having similar characteristics like smoking. The attitudes towards smoking may be different in smokers and non-smokers. There is increasing evidence to show that peer influence is a pivotal factor in adolescent smoking. Smoking is often a way for adolescents to instantly become independent and fit in with peers who smoke. Relationship of peers with smoking is complex and may influence or deter smoking [8].

Literature suggests that $89.8 \%$ of users start smoking before 19 years of age [9]. However, there is limited evidence for differences in peer pressure and attitudes in adolescent smokers and non-smokers. In the context of the abovementioned statistic, our study addresses this gap in the existing knowledge regarding differences in peer pressure and attitudes in adolescent smokers and non-smokers in college students of age group 1820 years. The primary aims of this study were to study the prevalence of smoking and age of initiation in urban college students, and to compare peer preferences and indicators of use in smoker and non-smoker college students.

\section{METHODOLOGY}

The study was conducted in second year degree college students in a large metropolitan city in India. A semi structured proforma containing details pertaining to socio demographic variables, The Global Youth Tobacco Survey (GYTS) [10] and the Evers Pasquale's peer preference test [11] was used. After informed consent was obtained, students (study participants) were interviewed with the peer preference test. Proformas were distributed in the classroom and returned after completing them.

A total sample of 100 was obtained from 119 second year degree college students with an inclusion rate of $84.03 \%$. Students were divided in two groups depending on current tobacco use. Smokers were defined as anyone who had smoked at least 100 cigarettes in their life and who currently smokes cigarettes [12]. Nonsmokers included never smoked and experimental smokers who were currently not smoking in the last 30 days. Thus, two groups were formed, Group A: Current smokers $(n=54)$, and Group B: non-smokers and experimental smokers $(\mathrm{n}=46)$.

Ever Pasquale's peer preference test is a 12-item scale scored on a 4-point Likert rating where $\mathrm{No}=1$ and Yes $=4$. It assesses the likelihood of the adolescent engaging in any activity in four different scenarios if they were with their best friends, cool friends, people they don't like and when they were alone. Higher score indicates greater likelihood of the adolescent conforming to situations in presence of peers. Total score is obtained with the mean of summation of scores [11].

The Global Youth Tobacco Survey was used to assess tobacco use indicators like the attitudes and opinions of adolescents to smoking. The GYTS aims to track tobacco use among youth in countries around the world, using a common methodology and core questionnaire. It also makes it possible to recognize patterns and determinants of smoking. It is a self-administered scale assessing the tobacco use indicators [10].

\section{STATISTICAL ANALYSIS}

Statistics were performed using SPSS 10 software. Group differences were analysed using unpaired t test, ANOVA, non-parametric tests and Fishers test as applicable. Two tailed $\mathrm{p}$ value was obtained for all statistical analyses.

\section{RESULTS}

The prevalence of current smoking was $54 \%$. However, $64 \%$ of college students had ever smoked. Majority of the college students (64\%) in 18-20 years age group had ever smoked and $54 \%$ were current smokers. Six of the ten girls in the study currently smoked, whereas $53 \%$ of the college students got pocket money between INR 300-400. Students in both groups belonged to upper and middle socioeconomic class. Almost $44 \%$ of college students initiated smoking at or after 16 years of age, whereas only $4 \%$ of the entire sample initiated smoking before 10 years of age. Despite numerical differences, groups had no significant differences in sociodemographic variables like age, gender, disposable income (pocket money) and socioeconomic status (Table 
1). About $7.41 \%$ of group A and $13.04 \%$ of group B were girls. However, it did not achieve statistical significance.

The mean age of initiation of smoking was 14.34 years in group A and 15.1 years in experimental smokers in Group B. Only $7.41 \%$ of ever smokers initiated smoking before 10 years of age in our study. Most students $(44 \%)$ initiated smoking at or after 16 years of age (Table 1$)$.

Table 1: Sociodemographic profile of both groups

\begin{tabular}{|c|l|l|l|l|}
\hline Variable & $\begin{array}{l}\text { Group A } \\
\text { (N=54) } \\
\text { Mean } \pm \text { SD } \\
\text { N (\%) }\end{array}$ & $\begin{array}{l}\text { Group B } \\
\text { (N=46) } \\
\text { Mean } \pm \text { SD } \\
\text { N (\%) }\end{array}$ & Statistics & p value \\
\hline $\begin{array}{c}\text { Age of smoking (years) } \\
18.74 \pm 0.78\end{array}$ & $18.60 \pm 0.80$ & $\begin{array}{l}\mathrm{t}=0.83 \\
\mathrm{df}=98\end{array}$ & $0.407^{\mathrm{a}}$ \\
\hline $\begin{array}{c}\text { Gender Male } \\
\text { Female }\end{array}$ & $\begin{array}{l}50(92.59) \\
4(7.4)\end{array}$ & $\begin{array}{l}40(86.95) \\
6(13.04)\end{array}$ & $\mathrm{X}^{2}=1.389$ & $0.506^{\mathrm{b}}$ \\
\hline $\begin{array}{c}\text { Socioeconomic status } \\
\text { Upper class } \\
\text { Middle class }\end{array}$ & $\begin{array}{l}24(55.55) \\
24(44.44)\end{array}$ & $\begin{array}{l}26(56.52) \\
20(43.47)\end{array}$ & $\mathrm{X}^{2}=0.982$ & $1^{\mathrm{b}}$ \\
\hline $\begin{array}{c}\text { Pocket money (in INR) } \\
631.87 \pm 230.231\end{array}$ & $676.580 \pm 287.93$ & $\begin{array}{l}\mathrm{t}=0.987 \\
\mathrm{df}=98\end{array}$ & $0.986^{\mathrm{a}}$ \\
\hline
\end{tabular}

${ }^{a}$ Un-paired $t$ test used in the statistics, ${ }^{b}$ Chi-square test used in the statistics

It was found that $7.41 \%$ of group A and $26.09 \%$ of group B students had none of their closest friends as nonsmokers. More than half (53.7\%) of smoker participants reported that their parents were smokers. Both these results were statistically significant (Table 2).

Table 2: Groups and their Closest Friends as Smokers

\begin{tabular}{|c|c|c|c|}
\hline & $\begin{array}{l}\text { Group A } \\
(\mathrm{N}=54) \mathrm{N}(\%)\end{array}$ & $\begin{array}{l}\text { Group B } \\
(N=46) \text { N (\%) }\end{array}$ & Statistics \\
\hline None & $4(7.41)$ & $12(26.09)$ & \multirow{3}{*}{$\begin{array}{l}\mathrm{X}^{2}=6.4803 \\
\mathrm{p}=0.039^{*} \text { significant } \\
\mathrm{df}=2 \\
\text { Chi square test used in } \\
\text { calculation }\end{array}$} \\
\hline Some & $26(48.15)$ & $17(36.95)$ & \\
\hline Most / All & $24(44.44)$ & $17(36.95)$ & \\
\hline
\end{tabular}

Close to one fifth (18.52\%) of current smokers smoked daily and smoked cigarettes first in morning suggesting dependence. Though one third of Group A students did not admit to smoking daily, they expressed the desire to smoke first thing in the morning, indicating early signs of addiction. When both the groups were assessed on the GYTS (Table 3) differences in tobacco use indicators were seen. The majority of group B (non-smokers) opined that smoking made no difference in making friends for both the genders. $77.78 \%$ \& $83.33 \%$ of Group A (smokers) opined that smoking makes a difference in making friends in boys and girls respectively. The difference in attitudes in both the groups was statistically significant with smokers viewing a positive effect of smoking in social circle. 
Table 3 - Group data on having parents as smokers

\begin{tabular}{|l|l|l|l|}
\hline $\begin{array}{l}\text { Parents that } \\
\text { smoke }\end{array}$ & $\begin{array}{l}\text { Group A } \\
(\mathbf{n}=\mathbf{5 4 )} \mathbf{N}(\mathbf{\%})\end{array}$ & $\begin{array}{l}\text { Group B } \\
(\mathbf{n}=\mathbf{4 6}) \mathbf{N}(\mathbf{\%})\end{array}$ & Statistics \\
\hline No & $25(46.29)$ & $40(86.96)$ & $\begin{array}{l}\mathrm{p}<0.0001^{*} \\
\text { Fischer's exact test } \\
\text { used in the } \\
\text { calculation }\end{array}$ \\
\hline Both & $2(3.7)$ & $0(0)$ & \\
\hline Father only & $27(50)$ & $6(13.04)$ & \\
\hline
\end{tabular}

Majority of group A i.e., $75.93 \%$ opined that smoking makes attendance of social function more comfortable, whereas only $23.91 \%$ of group B opined that same. This difference was statistically significant. Positive effects of weight reduction by smoking were opined by $81.48 \%$ of group A and $43.48 \%$ of group B respondents. This difference was statistically significant \& in keeping with the other studies. $35.19 \%$ of group A and $78.26 \%$ of group B respondents thought that it is difficult to quit smoking once started and this difference was statistically significant.

When Group A was assessed on Ever Pasquale's peer preference test, it was shown that students who currently smoke are most likely to engage in any activity in the company of best friends, followed by cool friends. They were least likely to engage in any activity with people they didn't like. This difference was statistically significant $\left(\mathrm{p}<0.0001^{* * *}\right.$, Bartlett stat $\left.=20.379\right)$ (Table 4).

Table 4 - Scores between both groups of Evers-Pasquale Test

\begin{tabular}{|c|c|c|c|}
\hline & Group A $(n=54)$ & $\begin{array}{l}\text { Group B } \\
(\mathrm{n}=46)\end{array}$ & Statistics \\
\hline & \multicolumn{2}{|l|}{ Mean \pm SD } & \multirow{2}{*}{$\begin{array}{l}\text { Group A } \quad \text { A }<<0.0001^{*} \\
\text { Bartlett's Stat }=20.37\end{array}$} \\
\hline Best Friends & $3.231 \pm 0.322$ & $2.465 \pm 0.58$ & \\
\hline Cool Friends & $2.746 \pm 0.397$ & $2.171 \pm 0.61$ & \multirow{3}{*}{$\begin{array}{l}\text { Group B } \quad \text { B } \quad p<0.0001^{*} \\
\text { Bartlett's Stat }=1.298 \\
\text { *significant }(p<0.05)\end{array}$} \\
\hline Don't Like & $2.366 \pm 0.575$ & $1.813 \pm 0.553$ & \\
\hline Alone & $2.475 \pm 0.518$ & $2.365 \pm 0.652$ & \\
\hline
\end{tabular}

When Group B was assessed on Ever Pasquale's peer preference test, it was observed that they were most likely to engage in any activity with best friends followed by when they were alone. They were least likely to engage in any activity when alone. This difference was statistically significant $\left(\mathrm{p}<0.0001^{* * *}\right.$, Bartlett's stat $=1.29)($ Table 4$)$.

\section{DISCUSSION}

Smoking in women is not culturally and socially acceptable in India [13]. But current change in trend is seen with increased use in women in developing countries in response to marketing tactics [14]. The disposable income in terms of pocket money was and in group A \& B respectively. Researchers have found that availability of pocket money is related to smoking. However, we did not find any difference in both the groups [15].

Interestingly a gender bias was seen with group A opining that boys who smoke make more friends but girls who smoke have less friends. This probably reflects the poor cultural acceptance of smoking in women [16]. It was found that $7.41 \%$ of group A and $26.09 \%$ of group B students had none of their closest friends as non- 
smokers. Adolescents choose friends who are similar in characteristics and attitudes and this is seen strongly in non-smokers [7], which is consistent with our study. In Group A, $44.44 \%$ of the students had most or all of their friends as smokers. Adolescents whose more than three or almost all friends are smokers are more likely to be smokers [7]. More than half (53.7\%) of smoker participants reported that their parents were smokers, which is consistent with other studies showing adolescents who smoke were more likely to have smoker parents than non-smoker adolescents.

When both the groups were compared for peer preference, Group A was significantly more likely to initiate an activity in the company of best friends, cool friends and people they didn't like. There was no significant difference in situations when students from both the groups were alone. This shows that smokers are more likely to conform and be influenced in not just $\mathrm{n}$ the company of best and cool friends but also when they are with people whom they don't like. Smokers were greatly influenced by peers as compared to nonsmokers.

The main study limitations were that the study group does not represent the entire 18-20 years age group. Also, smoking was self-reported and not confirmed by any biochemical test.

\section{CONCLUSION}

The study results indicated that half of the students in smokers group had a dependence pattern. Smokers were more likely to have either or both parents as smokers and less likely to have any non-smoker close friend. Additionally, smokers are more likely to believe that smoking has positive effects like having more friends, making participation in social events more comfortable and causing weight loss. Approximately half to two-third of non-smokers felt that smoking makes no difference in making friends or being more comfortable. Compared to non-smokers, smokers minimized their perception of habitual smoking by underestimating the difficulty to quit. Though smokers and non-smokers maybe equally likely to participate in any situation when alone, smokers show a high likelihood of activity participation in the presence of any peer like best friends, cool adolescents and people they didn't like. Peer influence was significant in smokers. In addition to peer pressure, tobacco intervention programmes need to be directed at adolescent specific factors. Behavioural intervention and coping strategies need to targeted at these impressionable minds. Further, research is needed to understand other factors promoting smoking like personality factors, social influence, genetic factors etc.

\section{REFERENCES}

1. Sasco AJ, Secretan MB, Straif K. Tobacco smoking and cancer: a brief review of recent epidemiological evidence. Lung Cancer 2004;45:S3-9.

2. Hiscock R, Bauld L, Amos A, Fidler JA, Munafò M. Socioeconomic status and smoking: a review. Ann NY Acad Sci 2012;1248(1):107-23.

3. Schepis TS, Rao U. Epidemiology and etiology of adolescent smoking. Curr Opin Pediatr 2005;17(5):607-12.

4. Jindal SK, Aggarwal AN, Chaudhry K, Chhabra SK, D Souza GA, Gupta D, Katiyar SK, Kumar R, Shah B, Vijayan VK. Tobacco smoking in India: prevalence, quit-rates and respiratory morbidity. Indian J Chest Dis Allied Sci 2006;48(1):37-42.

5. Chaiton MO, Cohen JE, O'Loughlin J, Rehm J. A systematic review of longitudinal studies on the association between depression and smoking in adolescents. BMC Pub Health 2009;9(1):356.

6. Palmer RH, Young SE, Hopfer CJ, Corley RP, Stallings MC, Crowley TJ, Hewitt JK. Developmental epidemiology of drug use and abuse in adolescence and young adulthood: Evidence of generalized risk. Drug Alcohol Depend 2009;102(1-3):78-87.

7. O'loughlin J, Karp I, Koulis T, Paradis G, DiFranza J. Determinants of first puff and daily cigarette smoking in adolescents. Am J Epidemiol 2009;170(5):585-97.

8. Kiuru N, Burk WJ, Laursen B, Salmela-Aro K, Nurmi JE. Pressure to drink but not to smoke: Disentangling selection and socialization in adolescent peer networks and peer groups. J Adolescence 2010;33(6):801-12.

9. Simons-Morton BG, Farhat T. Recent findings on peer group influences on adolescent smoking. J Primary Prev 2010;31(4):191-208. 
10. Warren CW, Lea V, Lee J, Jones NR, Asma S, McKenna M. Change in tobacco use among 13-15year olds between 1999 and 2008: findings from the Global Youth Tobacco Survey. Glob Health Promot 2009;16(Suppl 2):38-90.

11. Evers-Pasquale WL. The Peer Preference Test as a measure of reward value: Item analysis, cross-validation, concurrent validation, and replication. J Abnorm Child Psychol 1978;6(2):175-88.

12. Fagerström K. The epidemiology of smoking. Drugs 2002;62(2):1-9.

13. Allen AM, Oncken C, Hatsukami D. Women and smoking: the effect of gender on the epidemiology, health effects, and cessation of smoking. Curr Addiction Rep 2014;1(1):53-60.

14. Sargent JD, Gibson J, Heatherton TF. Comparing the effects of entertainment media and tobacco marketing on youth smoking. Tobacco Contr 2009;18(1):47-53.

15. Ma J, Zhu J, Li N, He Y, Cai Y, Qiao Y, Redmon P, Wang Z. Cigarette smoking in Chinese adolescents: importance of controlling the amount of pocket money. Pub Health 2013;127(7):687-93.

16. Haines RJ, Poland BD, Johnson JL. Becoming a 'real'smoker: cultural capital in young women's accounts of smoking and other substance use. Sociol Health Illness 2009;31(1):66-80.

\footnotetext{
$* * * * * * * * * * * * * * * * * * * * * * * * * * * * * * * * * * * *$

Acknowledgements - Nil

Conflict of Interest - Nil;

Funding - Nil
} 